\title{
THE I3RC \\ Bringing Together the Most Advanced Radiative Transfer Tools for Cloudy Atmospheres
}

\author{
by Robert F. Cahalan, Lazaros Oreopoulos, Alexander Marshak, K. Franklin Evans, \\ Anthony B. Davis, Robert Pincus, Ken H. Yetzer, Bernhard Mayer, Roger Davies, \\ Thomas P. Ackerman, Howard W. Barker, Eugene E. Clothiaux, Robert G. Ellingson, \\ Michael J. Garay, Evgueni Kassianov, Stefan Kinne, Andreas Macke, William O'Hirok, \\ Philip T. Partain, Sergei M. Prigarin, Alexel N. Rublev, Graeme L. Stephens, Frederic Szczap, \\ Ezra E. Takara, Támas Várnal, Guoyong Wen, and Tatiana B. Zhuravleva
}

An international Intercomparison of 3D Radiation Codes (I3RC) underscores the vast progress of recent years, but also highlights the challenges ahead for routine implementation in remote sensing and global climate modeling applications.

M odeling atmospheric and oceanic processes is one of the most important methods of the earth sciences for understanding the interactions of the various components of the surface-atmosphere system and predicting future weather and climate states. Great leaps in the availability of computing power at continuously decreasing costs have led to widespread popularity of computer models for research and operational applications. As part of routine scientific work, output from models built for
AFFILIATIONS: CAHALAN-NASA Goddard Space Flight Center, Greenbelt, Maryland; OreOPOULOS, VÁRNAI, AND WEN-University of Maryland, Baltimore County, Baltimore, and NASA Goddard Space Flight Center, Greenbelt, Maryland; MARSHAK-NASA Goddard Space Flight Center, Greenbelt, and University of Maryland, Baltimore County, Baltimore, Maryland; Evans-University of Colorado, Boulder, Colorado; Davis—Los Alamos National Laboratory, Los Alamos, New Mexico; PINCUs-NOAA-CIRES Climate Diagnostics Center, Boulder, Colorado; YETZERRaytheon-ITSS, Beltsville, and NASA Goddard Space Flight Center, Greenbelt, Maryland; MAYER-Deutsches Zentrum für Luft und Raumfahrt, Oberpfaffenhofen, Germany; DAVIES-Jet Propulsion Laboratory, Pasadena, California; Ackerman AND KassianovPacific Northwest National Laboratory, Richland, Washington; BARKER-Meteorological Service of Canada, Downsview, Ontario, Canada; Clothiaux-The Pennsylvania State University, University Park, Pennsylvania; Ellingson and TaKara-The Florida State
University, Tallahassee, Florida; GARAY-University of California, Los Angeles, Los Angeles, California; KINNE-Max-Planck-Institut für Meteorologie, Hamburg, Germany; MACKE-Liebniz Institute for Marine Sciences, IFM-GEOMAR, University of Kiel, Kiel, Germany; O'HIROK-University of California, Santa Barbara, Santa Barbara, California; PARTAIN AND STEPHENS-Colorado State University, Fort Collins, Colorado; PrIGARIN-Institute for Computational Mathematics and Mathematical Geophysics, Novosibirsk, Russia; RuBlev-Kurchatov Institute, Moscow, Russia; SzCZAP-Université Blaise Pascal, Clermont-Ferrand, France; ZhuraVleVA-Institute of Atmospheric Optics, Tomsk, Russia CORRESPONDING AUTHOR: Robert F. Cahalan, NASA GSFC, Code 613.2, Greenbelt, MD 2077I

E-mail: Robert.F.Cahalan@nasa.gov DOI: 10.1175/BAMS-86-9-1275

In final form 9 May 2005

(C)2005 American Meteorological Society 
similar purposes is continuously being compared by compiling results scattered in the scientific literature. In the last few years, however, intercomparison efforts have also emerged in the form of centrally directed initiatives. Intercomparison of various aspects of atmospheric global climate models $(\mathrm{GCMs})^{1}$ is a good example of this (e.g., Cess et al. 1989), but numerical codes, focused on more specific atmospheric phenomena like cloud system resolving models (CSRMs) and large eddy simulation (LES) models, which simulate cloud life cycles, have also been compared (Moeng et al. 1996). In the field of radiative transfer (RT) for climate and remote sensing applications, the most prominent intercomparison projects of the last few years were the Intercomparison of Radiation Codes for Climate Models (ICRCCM) (Ellingson et al. 1991; Barker et al. 2003b) and the Radiation Transfer Model Intercomparison (RAMI) (Pinty et al. 2001; 2004). RAMI actually shares a unique feature with the subject of this paper, the international Intercomparison of 3D Radiation Codes (I3RC): it focuses on three-dimensional (3D) RT. While RAMI examines how solar radiation interacts with vegetated surfaces, I3RC studies how solar and thermal radiation interact with cloudy atmospheres.

Three-dimensional RT research in atmospheric sciences began in earnest with work in the early 1970s in the former Soviet Union (e.g., Mullamaa et al. 1972; Avaste and Vainikko 1974; Glasov and Titov 1975), expanded in the United States soon thereafter (e.g., McKee and Cox 1974; Davies 1978), and eventually appeared in atmospheric RT monographs (e.g., Lenoble 1985). Presently, it is considered an independent and mature research area. Current 3D RT investigations in cloudy atmospheres can be broadly divided in two major application areas: 1) remote sensing, and 2) radiative energy budgets.

Accurate remote sensing of cloud properties is largely driven by the desire of modelers to adequately represent them in GCMs because they play a major role in climate dynamics (e.g., Ramanathan et al. 1989; Fu et al. 1995; Kiehl and Trenberth 1997). The atmospheric and planetary science communities have known for a long time that the remote sensing of cloud properties using current one-dimensional (1D) RT is suspect because clouds are not $1 \mathrm{D}$, but $3 \mathrm{D}$, and the horizontal exchange of photons between different parts of a cloud or between clouds cannot be accounted for by $1 \mathrm{D}$ theory. That 3D RT effects are indeed omnipresent in cloud observations from space

\footnotetext{
${ }^{1}$ A full list of acronyms is provided in the appendix.
}

has been well documented since the Landsat satellite era (e.g., Wielicki and Welch, 1986). The significant errors in 1D or "plane parallel" cloud retrievals have been quantified using increasingly realistic models of 3D cloud structure (e.g., Cahalan 1989; Chambers et al. 1997; Várnai and Marshak 2002), but accounting for 3D effects in an operational environment is a goal that has yet to be accomplished.

The cloud and climate modeling community is further ahead of its remote sensing counterpart in incorporating the advances of 3D RT into its representation of radiative processes. This is not only because a forward problem is almost always more tractable than an inverse problem, but also because GCMs are only interested in large-scale averages of angularly integrated radiation fields-that is, fluxes of radiation at the boundaries of atmospheric columns, and the vertical rates of flux change within atmospheric columns, which relate directly to internal heating rates. Such coarse radiation fields are faster to calculate and less error prone than the angularly and spatially detailed radiances of interest in remote sensing (i.e., "pencils" of radiation measured by satellite radiometers). Despite this advantage, there is still much room for improvement in the way GCMs handle unresolved cloud variability within grid cells at both solar and thermal wavelengths.

The 1D Independent Column Approximation (ICA) is presently the most popular framework for improving GCM parameterizations of broadband (spectrally integrated) RT. ICA resolves subgrid variability by averaging results for individual vertical columns, but does not allow for radiation to be exchanged between columns. Its popularity and usefulness stems from the fact that, for many different cloud types and conditions, it gives domain-averaged results that are close to the full 3D results (e.g., Cahalan et al. 1994; Barker et al. 1998; Barker et al. 1999). However, as new modeling breakthroughs, such as the Multiscale Modeling Framework (MMF) or "superparameterization" (Randall et al. 2003), make explicit representation of subgrid cloudiness on a global scale a reality, it is no longer obvious that certain aspects of 3D RT can be safely ignored. In other words, MMF cloud fields may be so highly resolved $(\sim 1 \mathrm{~km})$ in the near future that errors associated with the neglect of radiative interactions between cloudy columns will become blatantly obvious.

The goal of I3RC is to promote the improvement of algorithms that are used for all kinds of 3D RT processes in cloudy atmospheres. Activities include not only comparisons of results from state-of-the-art 3D RT codes, but also development of fast approxima- 
tions that are more suitable for climate applications and commmunity "open source" codes that distill the best current knowledge on how to treat the various interactions of ultraviolet, visible, and infrared photons with atmospheric constituents. As such tools become standard in RT educational training, I3RC will benefit practitioners of atmospheric RT in both the modeling (GCM, CSRMs, LES, etc.) and the observational (e.g., remote sensing) communities. Beyond the principal goals of I3RC, which revolve around documentation of errors and limitations of 3D methods, sharing and development of 3D tools, and atmospheric science education in $3 \mathrm{D}$ RT, the project also aspires to a series of related specific goals that will

- delineate acceptable error tolerance for radiances, which are the cornerstone of remote sensing from space;

- contribute to error detection and improvement in the participating codes;

- reveal requirements for future generation surface cloud-probing instruments;

- guide the development of techniques that produce or predict subresolution variability; and

- generate momentum for continuing and expanding observational and modeling efforts that analyze and forecast three-dimensional cloud fields.

I3RC is proceeding in three phases. The first two phases have been largely completed, and will be further discussed in the sections that follow. Two workshops, hosted by the University of Arizona, have taken place to discuss the results and lessons learned from each phase, and a Web site dedicated to I3RC has been created. Phase 3 is currently underway with a third workshop, hosted by the University of Kiel, scheduled to take place in October 2005, in Kiel, Germany. It uses 3D cloud fields that are reconstructed from combined simultaneous observations from instruments aboard the Terra satellite (potentially including ASTER, MISR and MODIS), and emphasizes improving, extending, and sharing RT modules, aided by two working groups. The "Approximations" working group, led by Anthony Davis, considers deterministic approximate methods in an attempt to gain advantages in execution time, and also to advance the understanding of $3 \mathrm{D}$ radiation processes for eventual implementation of these algorithms into other models. The "Open Source" working group, led by Robert Pincus, is developing a Monte Carlo RT code that is distributed publicly, thus, making a state-of-the-art tool available to a wide range of users. Activities of both working groups are further elucidated in two subsequent sections.

I3RC PHASE I. During Phase I, which is now complete, several baseline 3D RT computations on three cloud fields were performed. The three cloud fields were an idealized 1D "step" cloud field, a 2D field derived from the ARM cloud radar, and a 3D field derived from radiances measured by the Landsat- 4 Thematic Mapper instrument (Fig. 1). In November 1999, participating members of 18 research groups, representing several countries, met and compared their results for the various experiments of Phase I. The computations were monochromatic (single wavelength, not explicitly specified), with cloud droplet scattering and absorption only (no emission). Scattering and absorption by other atmospheric constituents
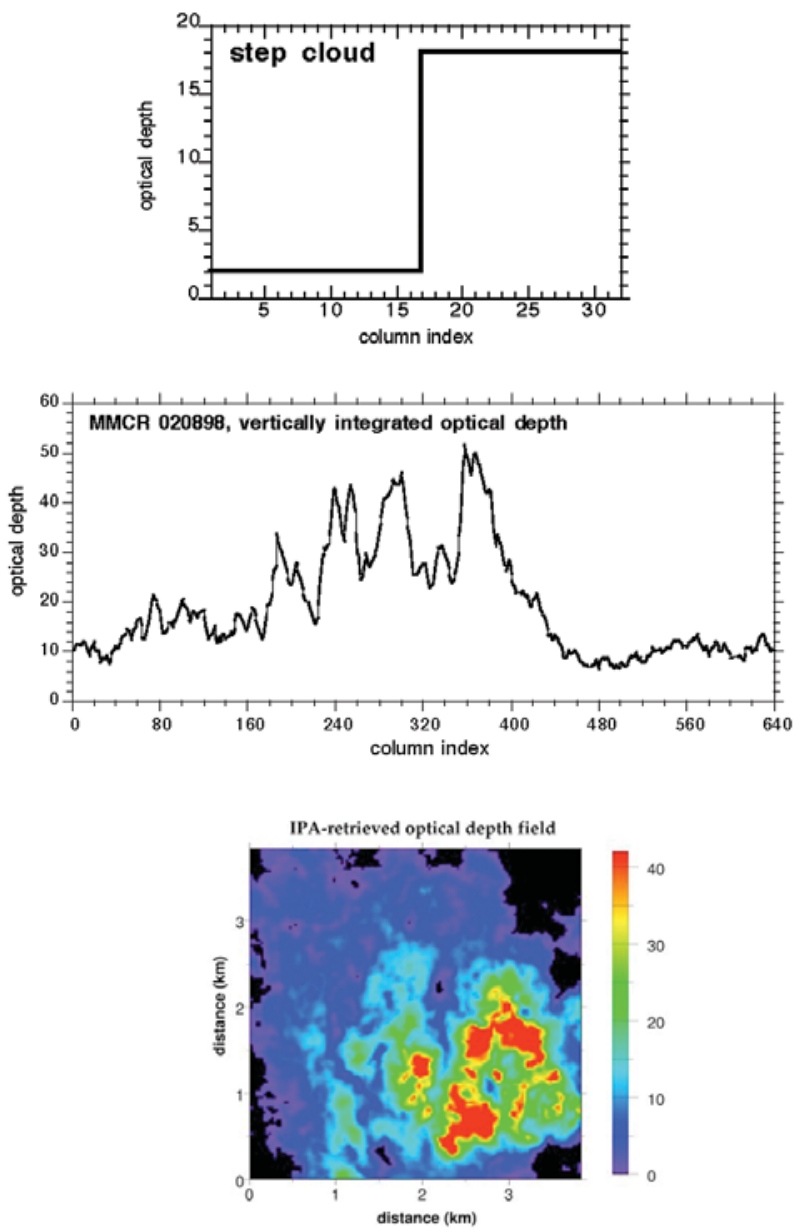

FIG. I. Integrated visible optical thickness for the three cloud fields of I3RC phase I: (top) case I, called "step cloud"; (middle) case 2, based on millimeter radar observations; and (bottom) case 3 , based on retrievals from high-resolution Landsat radiance measurements. 
Here we briefly present the two 3D RT tools that are currently dominating atmospheric radiation applications, namely the Spherical Harmonic Discrete Ordinate Method (SHDOM) of Evans (1998) and the Monte Carlo (MC) method (Marchuk et al. 1980). These two methods (both thoroughly described in Marshak and Davis 2005), while being completely different in their approach for solving the 3D RT problem, are currently the only available options for dealing with the full suite of problems put forth by I3RC.

SHDOM is the most widely used explicit multidimensional RT model in the atmospheric sciences. This is because it is efficient, flexible, user friendly, and publicly available. SHDOM computes unpolarized monochromatic or spectral band RT in a one-, two-, or three-dimensional medium for either collimated (i.e., nondiffuse) solar and/or thermal emission sources of radiation. The optical properties of the medium can be specified completely generally. Radiances at any angle, hemispheric fluxes, net fluxes, mean radiances, and net flux convergence (related to heating rates) may be output anywhere in the domain. SHDOM uses an iterative process to compute the source function term of the RTE on a grid of points in space. The angular part of the source function is represented with a spherical harmonic expansion. Solving for the source function instead of the radiance field saves memory, because there are often parts of a medium where the source function is zero or angularly very smooth (hence, few spherical harmonic terms). The other reason for using spherical harmonics is that the scattering integral is more efficiently computed than in discrete ordinates. A discrete ordinate representation is used in the solution process because the streaming of radiation is more physically (and correctly) computed this way. An adaptive grid that chooses how to distribute grid points in space is useful in atmospheric RT because the source function is usually rapidly varying in some regions and slowly varying in others. When many radiative quantities are desired, for example, the radiance field across the domain top or the 3D distribution of heating, SHDOM is superior and faster than MC RT methods (described below), but its errors are harder to understand.

The MC methods are a general technique for constructing probabilistic models of real processes. In contrast to SHDOM, which solves the RTE explicitly, MC solves the same RTE statistically using probabilistic modeling of the associated RT processes. In its application to RT in the atmosphere, $\mathrm{MC}$ computes the flow of radiation by simulating the trajectories of photons emitted from a source, such as the sun for shortwave radiation, or surface and cloud elements for longwave radiation. The trajectories are determined probabilistically: the distance a photon travels before interaction with a scatterer, the probability that it survives a scattering event, and the direction of scattering after each interaction, are calculated by generating random numbers that provide probabilistic representations of the optical properties of the atmosphere.

The MC methods are valuable because they are exceedingly flexible, and because their accuracy is well understood and can be predicted by examining the variance between estimates made from subsets of the simulation. Also, MC may be superior to $\mathrm{SH}$ DOM for media with strong extinction gradients and/or large domains.

In "straightforward" Monte Carlo the radiative quantities of interest (fluxes, heating rates, radiances) are determined by counting the fraction of photons that meet a certain fate: domain-averaged reflectance, for example, is the fraction of photons that exit from the top of the domain. The straightforward approach is very simple but, as I3RC has confirmed, absolutely impractical for the solution of complicated problems, such as computing the spatially dependent radiance field above and/or below a variable patch of clouds and reflective surface. The difficulty stems from several causes, including the strongly forward-peaked scattering phase functions (functions describing the dependence of scattered radiance on scattering angle) exhibited by cloud drops, and the multiple scattering that occurs in optically dense media, like clouds. The former increases the variance of the MC estimate, while the latter increases the execution time of $M C$ codes. To improve MC performance, techniques such as "maximum cross section" and "local estimate" have been implemented to simplify the codes, reduce variance, and speed up the runs. Both techniques, as well as others, are described in the Marchuk et al. (1980) monograph, which remains the single best reference on $M C$ simulations of RT in the atmosphere. (gases, aerosols) were ignored to ensure that any differences originated only from the treatment of cloudradiation interactions. Computations were completed independently and blindly (i.e., without access to the calculations of others) at the participants' home institutions. Extensive results are summarized on the I3RC Web page (see later section) at http://i3rc.gsfc. nasa.gov. Results for at least one experiment (although not necessarily the complete set) were provided by 22 different 3D algorithms (Table 1).
Cloud fields, requested output, and submission strategy. The three cloud fields that were selected represented a wide range of size and complexity, and therefore, computational demands. The cases were designed so that a large number of 3D modelers who were able to run at least one case would be attracted to the project, while at the same time participating models would be tested to their limits in terms of computation time and memory use. 


\begin{tabular}{|c|c|c|c|c|c|}
\hline No. & Code & Institution & $\begin{array}{l}\text { Contact } \\
\text { person }\end{array}$ & Reference & Method description \\
\hline I & ARIZ (United States) & $\begin{array}{l}\text { Formerly University of } \\
\text { Arizona, now at UCLA }\end{array}$ & M. Garay & Davies (1978) & Monte Carlo \\
\hline 2 & COLS (United States) & Colorado State University & P. Partain & $\begin{array}{l}\text { Partain } \\
\text { et al. }(2000)\end{array}$ & Monte Carlo \\
\hline 3 & IAOT (Russia) & $\begin{array}{l}\text { Institute of Atmospheric } \\
\text { Optics }\end{array}$ & T. Zhuravleva & $N / A$ & Monte Carlo \\
\hline 4 & KIAEI (Russia) & Kurchatov Institute & A. Rublev & $\begin{array}{l}\text { Geogdzhaev } \\
\text { et al. (1997) }\end{array}$ & Monte Carlo \\
\hline 5 & KIAE2 (Russia) & Kurchatov Institute & A. Rublev & $\begin{array}{l}\text { Rublev et al. } \\
(2004)\end{array}$ & $\begin{array}{l}\text { Monte Carlo using adjoint } \\
\text { RTE }\end{array}$ \\
\hline 6 & LANLI (United States) & $\begin{array}{l}\text { Los Alamos National } \\
\text { Laboratory }\end{array}$ & A. Davis & Qu (1999) & $\begin{array}{l}\text { 3D delta-Eddington (ED3D) } \\
\text { diffusion model }\end{array}$ \\
\hline 7 & LANL2 (United States) & $\begin{array}{l}\text { Los Alamos National } \\
\text { Laboratory }\end{array}$ & A. Davis & $\begin{array}{l}\text { Davis et al. } \\
\text { (199I) }\end{array}$ & $\begin{array}{l}\text { DA (six-beam PDE model, } \\
\text { using Monte Carlo) }\end{array}$ \\
\hline 8 & LANL3 (United States) & $\begin{array}{l}\text { Los Alamos National } \\
\text { Laboratory }\end{array}$ & A. Davis & $\begin{array}{l}\text { Alcouffe et al. } \\
(1997)\end{array}$ & TWODANT \\
\hline 9 & MESCI (Canada) & $\begin{array}{l}\text { Meteorological Service of } \\
\text { Canada }\end{array}$ & H. Barker & $\begin{array}{l}\text { Barker et al. } \\
(2003 a)\end{array}$ & Monte Carlo \\
\hline 10 & MESC2 (Canada) & $\begin{array}{l}\text { Meteorological Service of } \\
\text { Canada }\end{array}$ & H. Barker & $\begin{array}{l}\text { Barker et al. } \\
(2003 a)\end{array}$ & $\begin{array}{l}\text { Monte Carlo, delta-scaled } \\
\text { optical properties }\end{array}$ \\
\hline II & NCAR (Germany) & Formerly NCAR, now DLR & B. Mayer & $\begin{array}{l}\text { Mayer and } \\
\text { Kylling (2005) }\end{array}$ & Monte Carlo, libRadtran \\
\hline 12 & PENN (United States) & $\begin{array}{l}\text { The Pennsylvania State } \\
\text { University }\end{array}$ & E. Clothiaux & Cole (2005) & Monte Carlo \\
\hline 13 & PNNL (United States) & $\begin{array}{l}\text { Pacific Northwest National } \\
\text { Laboratory }\end{array}$ & E. Kassianov & $\begin{array}{l}\text { Kassianov and } \\
\text { Kogan (2002) }\end{array}$ & $\begin{array}{l}\text { MC, max cross section, ex- } \\
\text { act first-order scattering }\end{array}$ \\
\hline 14 & UCOLI (United States) & University of Colorado & K. F. Evans & Evans (1998) & SHDOM, low resolution \\
\hline 15 & UCOL2 (United States) & University of Colorado & K. F. Evans & Evans (1998) & SHDOM, high resolution \\
\hline 16 & UCSB (United States) & $\begin{array}{l}\text { University of California, } \\
\text { Santa Barbara }\end{array}$ & W. O'Hirok & $\begin{array}{l}\text { O'Hirok and } \\
\text { Gautier (1998) }\end{array}$ & Monte Carlo \\
\hline 17 & UMBCI (United States) & $\begin{array}{l}\text { Formerly UMBC, now at } \\
\text { GSFC }\end{array}$ & A. Marshak & $\begin{array}{l}\text { Marshak et al. } \\
\text { (1995) }\end{array}$ & $\begin{array}{l}\text { Monte Carlo, local max } \\
\text { cross section }\end{array}$ \\
\hline 18 & UMBC2 (United States) & $\begin{array}{l}\text { University of Maryland, } \\
\text { Baltimore County }\end{array}$ & T. Várnai & $\begin{array}{l}\text { Várnai and } \\
\text { Marshak (2002) }\end{array}$ & $\begin{array}{l}\text { Monte Carlo, max cross } \\
\text { section }\end{array}$ \\
\hline 19 & UMBC3 (United States) & $\begin{array}{l}\text { Formerly UMBC, now at } \\
\text { Max Planck Institute }\end{array}$ & S. Kinne & $N / A$ & Monte Carlo \\
\hline 20 & UMBC4 (United States) & $\begin{array}{l}\text { Formerly UMBC, now at } \\
\text { Max Planck Institute }\end{array}$ & S. Kinne & $N / A$ & $\begin{array}{l}\text { DA (six-beam discrete-space } \\
\text { model, using relaxation) }\end{array}$ \\
\hline 21 & UNBPI (France) & Université Blaise Pascal & F. Szczap & $\begin{array}{l}\text { Faure et al. } \\
(2001)\end{array}$ & Neural networks \\
\hline 22 & UNBP2 (France) & Université Blaise Pascal & F. Szczap & $\begin{array}{l}\text { Marshak et al. } \\
\text { (1998) }\end{array}$ & NIPA \\
\hline 23 & UNIK (Germany) & University of Kiel & A. Macke & $\begin{array}{l}\text { Macke et al. } \\
\text { (1999) }\end{array}$ & Monte Carlo \\
\hline
\end{tabular}


CASE I, called "step-function cloud" or "square-wave cloud," was the simplest cloud field (Fig. 1, top), consisting of 32 columns (pixels) of equal width along the $\mathrm{x}$-direction, the first 16 having an optical depth of 2 , and the remaining having an optical depth of 18. The horizontal size of the entire field was set to $0.5 \mathrm{~km}$. The geometrical thickness of the cloud (along the $\mathrm{z}$-axis) was set to $0.25 \mathrm{~km}$ everywhere (flat-top cloud). In this simple, idealized case the main interest is model behavior in the vicinity of the single isolated jump in optical thickness.

CASE 2, called the radar cloud," was a cloud field inferred from MMCR and MWR measurements (Fig. 1, middle). The field consists of 640 columns along the $\mathrm{x}$ direction, each of which was set to $50 \mathrm{~m}$ horizontal width, and was vertically resolved into 54 vertical layers of $45 \mathrm{~m}$ thickness ( $\mathrm{z}$ direction).

CASE 3, called the "Landsat cloud," was a cloud field inferred from an IPA retrieval on a $128 \times 128$ subregion of a Landsat- 4 scene used in Oreopoulos and Davies (1998). The pixel size was $(30 \mathrm{~m})^{2}$ and cloudy pixels were assigned cloudtop heights based on atmospheric window brightness temperatures.

Case 1 and 3 experiments involved changes in illumination (sun) angle and single scattering albedo (probability of a photon surviving after an interaction with a cloud particle), and case 2 experiments involved changes in illumination angle, single scattering albedo, particle scattering phase function, and surface albedo.

Comparison methodology. In intercomparison exercises like I3RC, where true answers are not available, absolute model accuracy is not the main focus. The objective is not to find the "best" model, but to identify and understand the spread of submitted results. GCM intercomparisons are good examples of how this objective is pursued (Cess et al. 1989, 1990, 1996). Nonetheless, when all participating models are known to use approximations to model the cloudy atmosphere, the availability of benchmark results ("truth") from a model that does not (to the greatest degree possible) make approximations is extremely useful and instructional. Such was the case in the intercomparison of $1 \mathrm{D}$ GCM RT algorithms, where 3D benchmark results were available (Barker et al. 2003b). I3RC, with both "exact" and "approximate" model participation, falls somewhere in the middle, and faces challenges similar to RAMI (Pinty et al. 2001, 2004). The models were intercompared using estimates of:

- their first three moments (mean, standard deviation, skewness);

- cross correlations with one of the participating models (UMBC1);

- root-mean square (rms) deviations from one of the participating models (UMBC1);

- the median of the absolute deviation from one of the participating models (UMBC1).

$\mathrm{UMBC} 1$ was chosen as the reference code largely for reasons of convenience, because it was the code used at the home institution that directed the intercomparison (GSFC-UMBC), and could, therefore, be
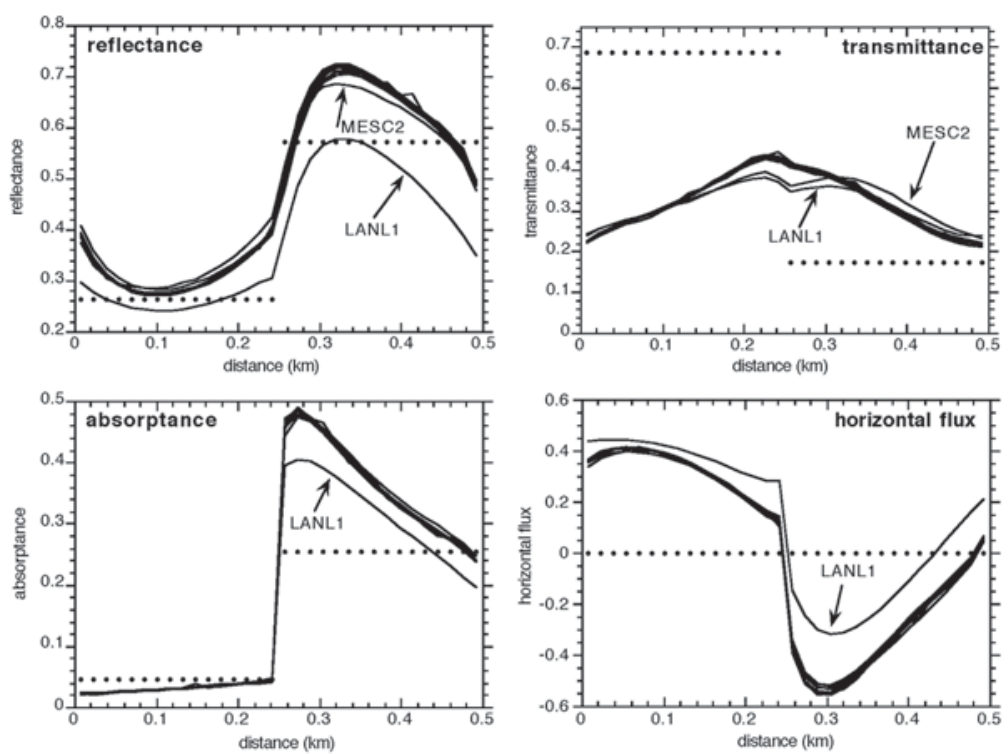

Fig. 2. Reflectance $(R)$, transmittance $(T)$, absorptance $(A)$, and horizontal flux $H=1-R-T-A$ for experiment 4 , case $I$, of phase I ("step cloud") from 18 participating codes. The single scattering albedo is 0.99 , the scattering phase function is that of Henyey-Greenstein with asymmetry factor (mean cosine of the scattering angle) $g=0.85$, the solar zenith angle is $60^{\circ}$ (sun shining from left), the surface is black (nonreflecting), and periodic boundary conditions in the horizontal are used. Only outliers are identified (see Table I), and predictably, both are approximation methods. But these are still better than the ICA [independent pixel approximation (IPA)] approximation (no horizontal flux allowed), which is identified by the black dots and which comes from calculations using the DISORT code. 
used for test runs before the experiments were publicly released; it also provided the full output dataset that was requested for Phase I.

Results. After results were intercompared at the 1999 workshop, several participants revisited their calculations in order to eliminate the possibility of erroneous interpretation of input or requested output and to reexamine the robustness of their codes. The complete Phase I results currently posted on the I3RC Web site are the final submissions after this second round of calculations. Here we provide two examples to give an idea of how the intercomparison was conducted and what the typical level of agreement was. Figure 2 shows results for experiment 4 of case 1 (step cloud). Eighteen codes participated in this experiment, but only the models that are outliers are identified. Both outliers use approximations that are geared for the computation of radiative fluxes: LANL1 uses diffusion theory to approximate multiple scattering, while MESC2 is a regular MC code that uses $\delta$ scaling (e.g., Thomas and Stamnes 1999, 190-197) of optical properties for all portions of the cloud that are more than a unit optical depth from the cloud top, in order to accelerate computations. All other models are barely distinguishable for all three components of the flux field (horizontal flux $H$ is only a residual). Note that $H$ is only different from zero in a real three-dimensional application (e.g., Marshak et al. 1999), and is, therefore, a good measure of the impact of cloud inhomogeneity, and of the capability of the different models to treat it correctly (due to energy conservation $H=0$ for domain averages, even for $3 \mathrm{D})$. ICA is conspicuously worse in its spatial distribution of fluxes than any of the approximate 3D methods, although it performs better for domain averages (e.g., its mean reflectance is closer to that of UMBC1 than of LANL1).

Figure 3, indicates that all participants can capture the main spatial features of radiance fields. For the MC fields (all but UCOL1), the noisiness of the field is a function of the number of photons used and the method of radiance calculation, that is, the "cone" method (e.g., Várnai and Davies 1999) versus "local
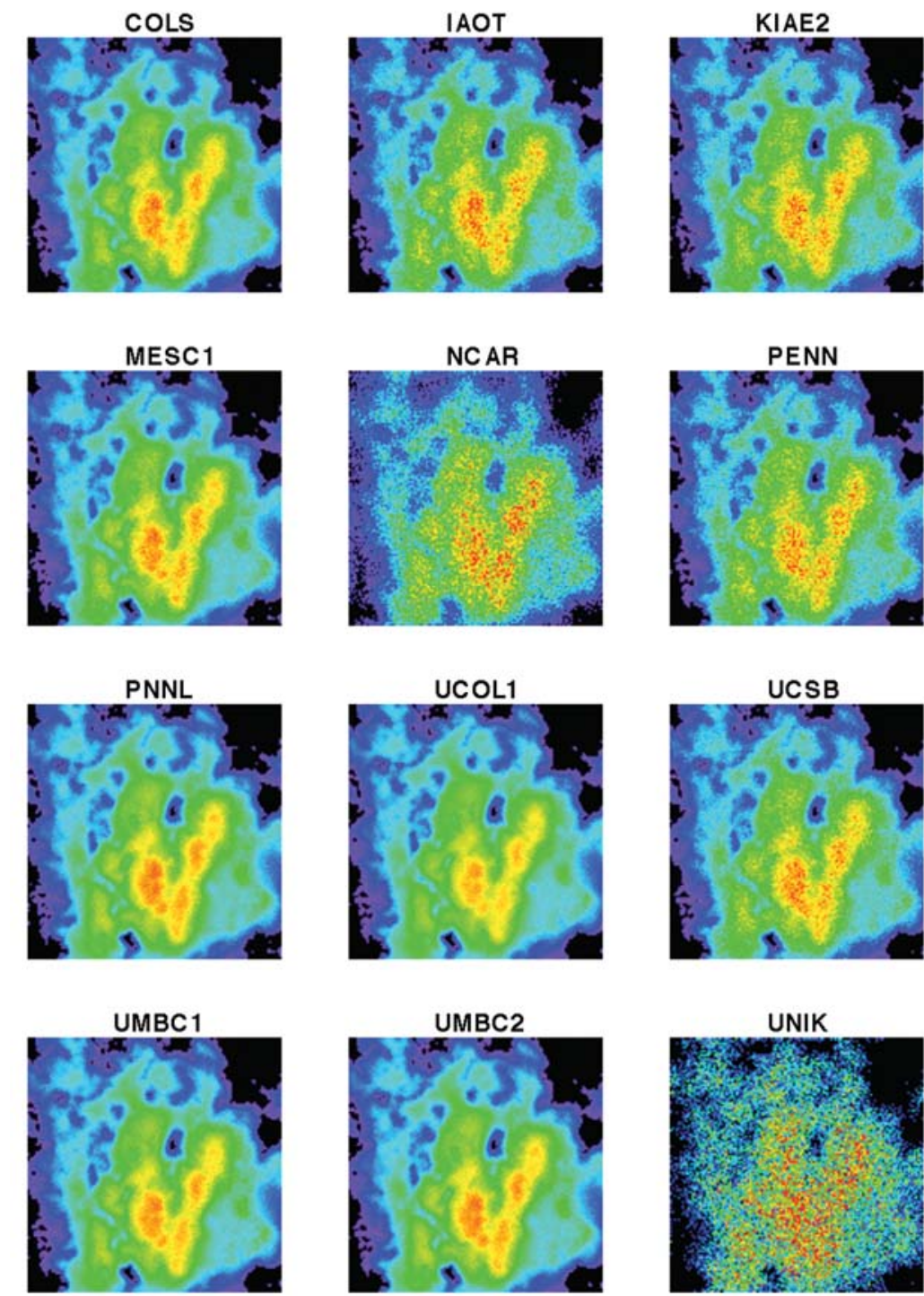

FIG. 3. Nadir radiance (bidirectional reflectance) fields of selected submissions for experiment 4 of case 3 (the Landsat field of Fig. I) of I3RC phase I. The input parameter values are the same as in the step-cloud case shown in Fig. 2. The colors represent a range of values extending from $\mathbf{0}$ (black) to $\mathbf{0 . 8}$ (red). It can be seen that all participants capture the main spatial features of the radiance field, while for the MC fields (all but UCOLI) the noisiness of the field is a function of the number of photons used and the method of radiance calculation, i.e., "cone" method (e.g., Várnai and Davies 1999) vs “local estimate” method (e.g., Marshak et al. 1995). Even the noisiest of the submissions manage to capture the mean radiance field quite accurately (Fig. 4). 
estimate" method (e.g., Marshak et al. 1995). It should be stressed, however, that even the noisiest of the submissions manage to capture the mean radiance field quite accurately. This is demonstrated in Fig. 4, which shows the domain average of the radiance field of each submission. Only two fields differ by $\approx 0.01$ ( $\approx 3.5 \%)$ from the consensus mean, while the noisiest field (UNIK), which corresponds to a code using the cone method, appears to be very close to the consensus mean, even though it has by far the largest standard deviation. The ICA (again from DISORT) has a domain average that is very similar to that of the 3D algorithms, but its smoother field (see insert field in Fig. 4) produces a significantly lower standard deviation due to its inability to model the illumination of cloud sides under oblique sun angles, which tends to amplify radiative gradients. In the language of 3D RT practitioners, ICA cannot simulate the "radiative roughening" of the full 3D calculation (e.g., Oreopoulos et al. 2000; Várnai and Marshak 2002). Note that this is the opposite of what happens at high sun elevations where ICA cannot simulate the "radiative smoothing" of multiple scattering in $3 \mathrm{D}$, that is, the reduced variability of the radiation field at small scales compared to that of the cloud structure, therefore, yielding more variable radiation fields (Marshak et al. 1995).

I3RC PHASE II. In Phase II of I3RC, more complex computations for two broad application areas were compared: "remote sensing" (dealing mainly with radiances) and "heating rate" (dealing mainly with radiative fluxes and internal heating rates). The computations were performed on a stratiform and a convective cloud field, each simulated with a different LES model (Fig. 5). Other than the requirement to produce heating rates, Phase II computations were also different than those of Phase I in the sense that they included effects of gases and aerosols in some experiments, non-Lambertian (anisotropically reflecting) surfaces in selected experiments, realistic remote sensing conditions in several experiments (e.g., off-nadir bidirectional reflectances were requested at multiple angles), and broadband and/or thermal calculations in a few experiments. Participating groups were asked to port their code to a Linux workstation provided by NASA GSFC. This was meant to allow for timing comparisons for a subset of the experiments, and to facilitate contributions to an "open source" public library for solving 3D RT problems. Results of Phase II computations can also be found at the I3RC Web site. Due in part to the complexity of Phase II cases, fewer codes (13) participated than in Phase I (see Table 2). The only non-MC code was SHDOM.

Cloud fields, application areas, and experiments. Phase II consisted of two main application areas:

- radiance fields for cloud remote sensing, and

- 3D heating rate fields for cloud and GCM modeling applications.

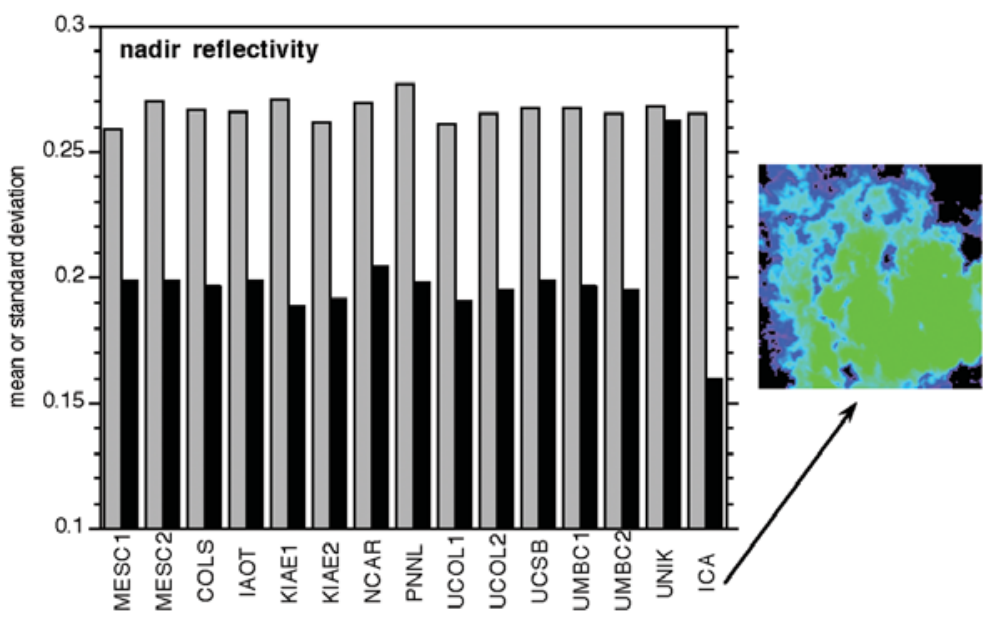

FIG. 4. Domain-averaged nadir reflectivity (gray bars) and std dev (black bars) for all models that participated in the I3RC phase I experiment shown in the previous figure. The last pair of columns correspond to the ICA, which was calculated using DISORT. The reflectivity field corresponding to ICA is also shown in order to highlight the radiative roughening caused by full 3D radiative transfer under the particular solar geometry.
All experiments were run for two LES model cloud fields (Fig. 5) and two different numerical accuracies: "high" and "low" (i.e., numbers of photons for MC methods and number of discrete ordinates in $\mathrm{SH}$ DOM). We also evaluated the CPU time-accuracy tradeoff of the participating models for a subset of the experiments. LES model output was selected for convenience because it provides a complete $3 \mathrm{D}$ description of the cloud fields. The two cloud fields were a) a cumulus $(\mathrm{Cu})$ cloud field from Stevens et al's (1999) LES modeling of the GCSS continental shallow cumulus boundary layer (ARM Oklahoma site) experiment (Fig. 5, top) - the cloud field consists of $100 \times 100 \times 36$ cells with a grid size of $66.7 \mathrm{~m} \times 66.7 \mathrm{~m} \times 40 \mathrm{~m}$; and 


\begin{tabular}{|c|c|c|c|c|c|}
\hline \# & Code & Institution & $\begin{array}{l}\text { Contact } \\
\text { person }\end{array}$ & Reference & Method description \\
\hline 1 & $\begin{array}{l}\text { ARIZ } \\
\text { (United States) }\end{array}$ & $\begin{array}{l}\text { Formerly University of Arizona, } \\
\text { now at UCLA }\end{array}$ & M. Garay & Davies (1978) & Monte Carlo \\
\hline 2 & $\begin{array}{l}\text { DZLRI } \\
\text { (Germany) }\end{array}$ & $\begin{array}{l}\text { Deutsches Zentrum für Luft und } \\
\text { Raumfahrt }\end{array}$ & B. Mayer & $\begin{array}{l}\text { Mayer and } \\
\text { Kylling (2005) }\end{array}$ & Monte Carlo, libRadtran \\
\hline 3 & $\begin{array}{l}\text { DZLR2 } \\
\text { (Germany) }\end{array}$ & $\begin{array}{l}\text { Deutsches Zentrum für Luft und } \\
\text { Raumfahrt }\end{array}$ & B. Mayer & $\begin{array}{l}\text { Mayer and } \\
\text { Kylling (2005) }\end{array}$ & $\begin{array}{l}\text { Monte Carlo, libRadtran trun- } \\
\text { cated forward peak }\end{array}$ \\
\hline 4 & \begin{tabular}{|l|l|} 
IAOT \\
(Russia)
\end{tabular} & Institute of Atmospheric Optics & T. Zhuravleva & N/A & $\begin{array}{l}\text { Monte Carlo, max cross sec- } \\
\text { tion }\end{array}$ \\
\hline 5 & $\begin{array}{l}\text { ICOM } \\
\text { (Russia) }\end{array}$ & $\begin{array}{l}\text { Institute of Computational } \\
\text { Mathematics }\end{array}$ & S. Prigarin & N/A & $\begin{array}{l}\text { Monte Carlo, max cross sec- } \\
\text { tion }\end{array}$ \\
\hline 6 & $\begin{array}{l}\text { PENN } \\
\text { (United States) }\end{array}$ & The Pennsylvania State University & E. Clothiaux & Cole (2005) & Monte Carlo \\
\hline 7 & $\begin{array}{l}\text { PNNL } \\
\text { (United States) }\end{array}$ & $\begin{array}{l}\text { Pacific Northwest National } \\
\text { Laboratory }\end{array}$ & E. Kassianov & $\begin{array}{l}\text { Kassianov and } \\
\text { Kogan (2002) }\end{array}$ & $\begin{array}{l}\text { MC, max cross section exact } \\
\text { first-order scattering }\end{array}$ \\
\hline 8 & $\begin{array}{l}\text { UCOL } \\
\text { (United States) }\end{array}$ & University of Colorado & F. Evans & Evans (1998) & SHDOM \\
\hline 9 & $\begin{array}{l}\text { UCSB } \\
\text { (United States) }\end{array}$ & $\begin{array}{l}\text { University of California, Santa } \\
\text { Barbara }\end{array}$ & W. O’Hirok & $\begin{array}{l}\text { O'Hirok and } \\
\text { Gautier (1998) }\end{array}$ & Monte Carlo \\
\hline 10 & $\begin{array}{l}\text { UMBCI } \\
\text { (United States) }\end{array}$ & Formerly UMBC, now at GSFC & A. Marshak & $\begin{array}{l}\text { Marshak et al. } \\
(1995)\end{array}$ & $\begin{array}{l}\text { Monte Carlo, local max cross } \\
\text { section }\end{array}$ \\
\hline II & $\begin{array}{l}\text { UMBC5 } \\
\text { (United States) }\end{array}$ & $\begin{array}{l}\text { University of Maryland, } \\
\text { Baltimore County }\end{array}$ & T. Varnai & $\begin{array}{l}\text { Várnai and } \\
\text { Marshak (2003) }\end{array}$ & $\begin{array}{l}\text { Monte Carlo, max cross sec- } \\
\text { tion }\end{array}$ \\
\hline 12 & $\begin{array}{l}\text { UMCP } \\
\text { (United States) }\end{array}$ & $\begin{array}{l}\text { Formerly University of Maryland, } \\
\text { College Park, now at FSU }\end{array}$ & E. Takara & $\begin{array}{l}\text { Takara and } \\
\text { Ellingson (1996) }\end{array}$ & Monte Carlo, LW, backward \\
\hline 13 & $\begin{array}{l}\text { UNIK } \\
\text { (Germany) }\end{array}$ & University of Kiel & A. Macke & $\begin{array}{l}\text { Macke et al. } \\
(1999)\end{array}$ & $\begin{array}{l}\text { Monte Carlo, local estimation } \\
\text { for radiances }\end{array}$ \\
\hline
\end{tabular}

b) a stratocumulus ( $\mathrm{Sc}$ ) cloud field from Moeng et al.'s (1996) LES modeling of FIRE-I stratocumuli (see Fig. 5, bottom) - the cloud field consists of $64 \times 64 \times$ 16 cells with a grid size of $55 \mathrm{~m} \times 55 \mathrm{~m} \times 25 \mathrm{~m}$.

A major difference from the comparison methodology of Phase I was the use of the consensus mean of the participating models as the benchmark ("truth"), instead of the output of a particular model. In other respects the analysis of submitted radiation fields was carried out in a manner similar to Phase I.

Results. Here, we limit ourselves to only one representative example. Figure 6 shows nadir reflectance fields for experiment 7 applied to the LES cumulus cloud field. This experiment includes an absorbing and scattering atmosphere consisting of aerosols and gases above a Lambertian surface, and assumes a Mie phase function for the scattering particles (spherical liquid droplets, nonabsorbing for this experiment). It can be seen that only a few participants submitted results for this case (seven participants with eight codes), suggesting that, at the time, several codes did not have the capability to deal with clouds coexisting with a radiatively active atmosphere. For experiment 2 , which was otherwise identical to experiment 7 , except for atmospheric effects, more (12) submissions were available. It was nevertheless encouraging to see that there was fairly good agreement among the models that attempted experiment 7 . The level of agreement shown in Figs. 6 and 7 was typical of that for other Phase II experiments. ICA results from DISORT again illustrate the importance of $3 \mathrm{D}$ effects in remote sensing. Not only is the standard deviation of ICA lower than that of the 3D methods (for the reasons given in the Landsat example of Phase I), but this time the mean also deviates significantly. 


\section{I3RC Cumulus LES Optical Depth}

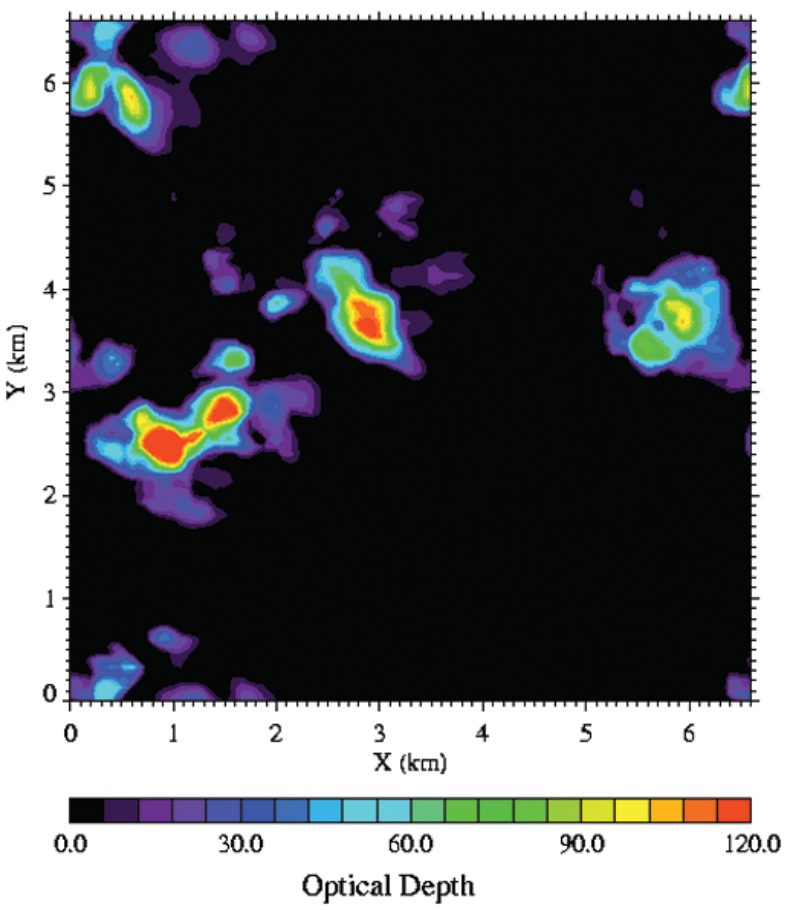

I3RC StCu LES Optical Depth

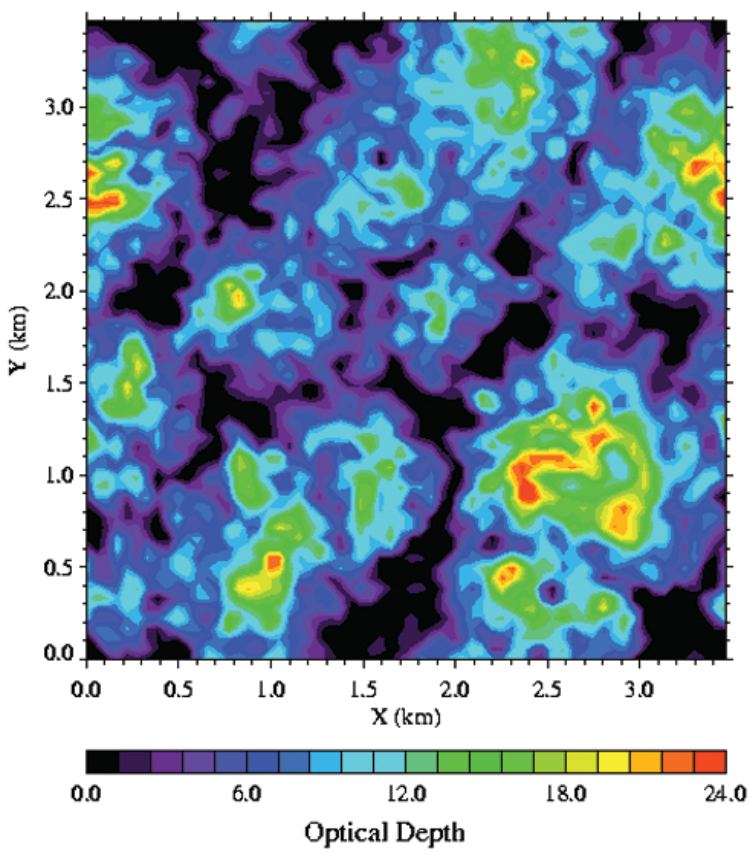

FIG. 5. Top-down view of integrated visible optical thickness field for the two LES cloud fields of I3RC phase II: (top) cumulus and (bottom) stratocumulus.
APPROXIMATIONS WORKING GROUP FOR 3D RT. This working group of I3RC, emerged from a desire to make available to $3 \mathrm{D}$ practitioners alternative algorithms to MC and SHDOM, which currently dominate as prime choices for attacking even the simplest 3D RT cloud problems. The main driver for going beyond MC and SHDOM is the need for better computational efficiency when, at the same time, only the first-order effects of 3D RT are of interest.

At the time of this writing, it is clear that this effort is far less advanced (in terms of contributions to the I3RC database) than the comparison between exact methods (which is itself dominated by MC methods). This is 1) because the atmospheric RT community is relatively new to the art of approximation in computational 3D transport theory, and 2) because the challenges are considerable, while the allocated resources are still meager. It is nevertheless instructive to discuss in more detail what the working group is about, what its goals are, and how I3RC plans to achieve them.

I3RC has compiled an extensive, but probably not exhaustive, list of deterministic 3D RT approximation models that comply with the output requests for I3RC participation (Table 3). This evolving list of 17 candidate models is grouped into three broad classes: a) truncated versions of 3D RTE solvers, b) solutions of new and simpler equations derived from the 3D RTE, and c) hybrid, or even ad hoc schemes based on an understanding of 3D RT phenomenology.

Because they produce radiation fields for given extinction fields and, thus, can be directly compared to "exact" methods, deterministic 3D RT approximation models have a natural place in I3RC. The difference, excluding class a, is that they numerically solve simpler sets of equations. Therefore, all classes considered, they are expected to be orders of magnitude faster than the MC and SHDOM methods of solving the full-blown 3D RTE. A well-known example is 3D diffusion theory (e.g., Davis and Marshak 2001), which can be derived from the RTE in a variety of ways. Such derivations give insight into where the approximation should and should not work. There are the folowing two levels of accuracy to ascertain:

- the physical accuracy of the alternate model (how well the simplified model approximates exact RT theory), and

- the mathematical accuracy of the implementation (how well we are numerically solving the new simplified equations). 

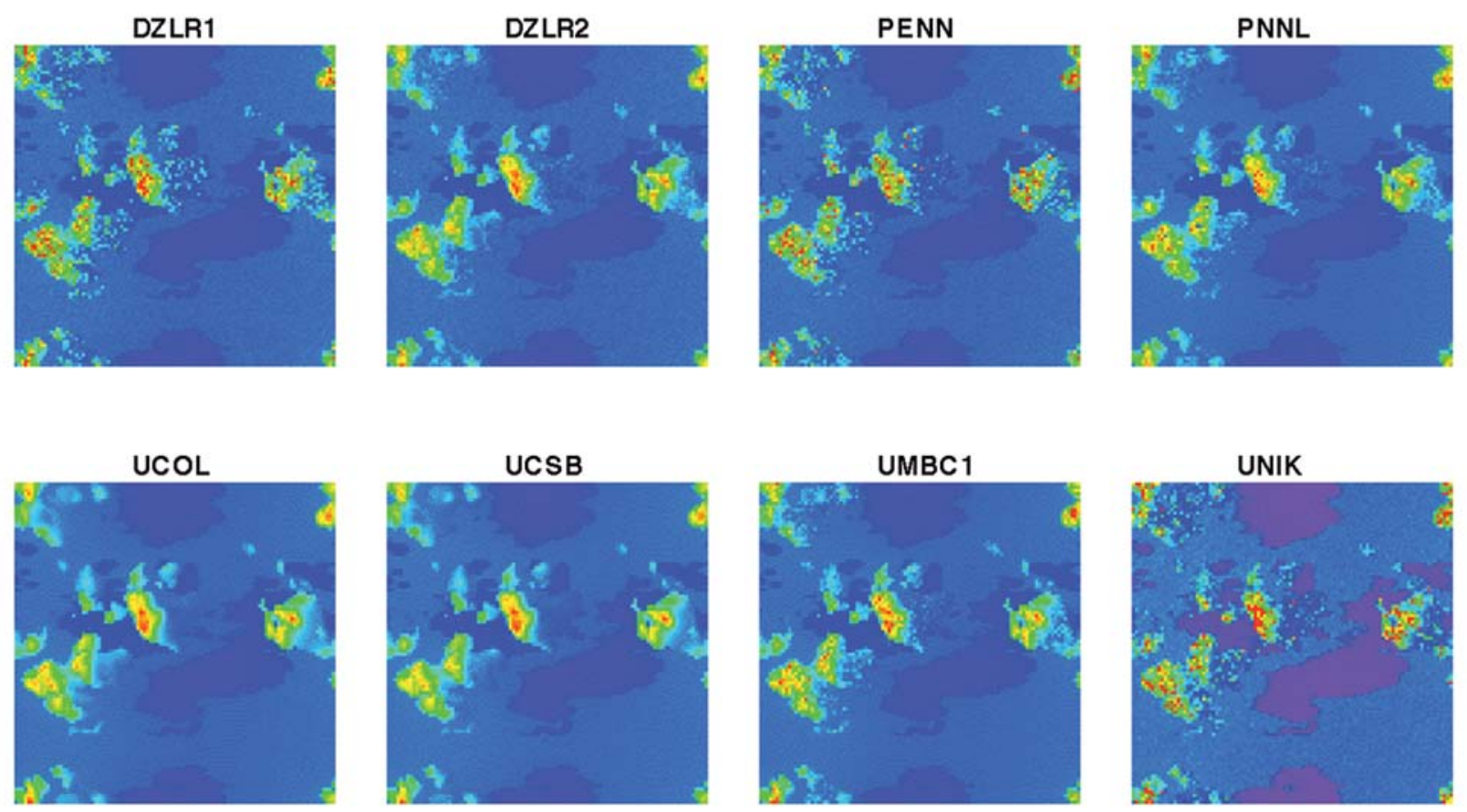

FIG. 6. High-accuracy nadir reflectance fields for the LES cumulus cloud field of phase II. The colors represent a range of values extending from 0 (violet) to $I .2$ (red). This is experiment 7 , which includes an absorbing and scattering atmosphere consisting of aerosols and gases and a reflecting Lambertian surface of 0.2 albedo; it assumes a Mie phase function for the scattering particles (spherical liquid droplets, nonabsorbing for this experiment). The sun is at a solar zenith angle of $60^{\circ}$ and is shining from the left side of the domain.

The latter concern needs to be addressed in view of the former. For instance, it would be unwise to implement a sixth-order precision solution of the diffusion equation, which is just a coarse approximation of the 3D RTE benchmark.

The prime application for deterministic approximation models is a situation, such as dynamical cloud modeling (LES or CSRM style), where computer time is a concern for every proposed enhancement. Another, longer-term, application would be computer-aided cloud optical tomography, where cloud shape and structure would be varied to fit a number of observations, that is, fully $3 \mathrm{D}$ cloud remote sensing.

Development and intercomparison of these codes is an ongoing effort that benefits from the I3RC benchmark calculations. Modelers are encouraged to use the same cases as in Phase I to produce the same outputs, starting with the simpler (fluxes), and then proceeding to the more difficult (radiances). However, the eventual goal is to have these models tackle the cases of Phase II, because they were designed purposefully to be very close to the level of detail required in the targeted applications.

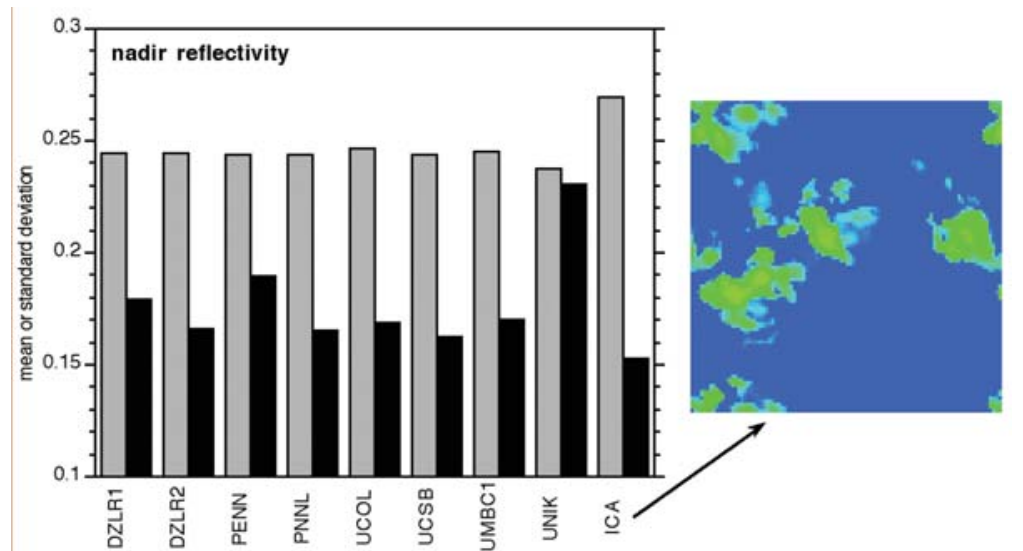

FIG. 7. Domain-averaged nadir reflectivity (gray bars) and std dev (black bars) for the fields shown in Fig. 6. The last pair of columns correspond to the ICA, which was calculated using DISORT. The reflectivity field corresponding to ICA is also shown in order to highlight the radiative roughening caused by full 3D radiative transfer under the particular solar geometry. 
TABLE 3. List of deterministic approaches for approximate 3D RT in their three broad categories. See appendix for name expansion of methods and participating institutions. The six entries in the third column mean that a contribution was made to the I3RC database (all were just for the case I step cloud). The II other methods are simply candidates identified either in the literature or at the break-out sessions of the Approximations Working Group. Documentation or application of these codes in scientific problems can be found in the papers entered in the reference column (see also reference list), whenever available.

\begin{tabular}{|c|c|c|c|}
\hline Description & Contact person(s), institution(s) & $\begin{array}{c}\text { I3RC } \\
\text { code } \\
\text { name }\end{array}$ & Reference \\
\hline \multicolumn{4}{|c|}{ Truncated versions of 3D RTE solvers } \\
\hline EVENT truncated at $L=I$ & C. de Oliveira (IMCL), N. Trasi (IMCL) & & Trasi et al. (2004) \\
\hline SHDOM truncated at $L=I$ & K. F. Evans (UCOL) & & Evans (1998) \\
\hline $\begin{array}{l}\text { Monte Carlo, rescaled optical } \\
\text { properties }\end{array}$ & H. Barker (MESC) & MESC2 & Barker et al. (2003a) \\
\hline Successive orders of scattering & R. Davies (JPL), M. Garay (UCLA) & & N/A \\
\hline \multicolumn{4}{|c|}{ Solutions of alternate equations that derive from the $3 D$ RTE } \\
\hline Adjoint perturbation theory & M. Box (UNSW), I. Polonsky (LANL) & & Polonsky et al. (2003) \\
\hline $\begin{array}{l}\text { Diffusion, finite differences } \\
\text { (ED3D) }\end{array}$ & Z. Qu (CIRES), A. Davis (LANL) & LANLI & Qu (1999) \\
\hline Diffusion, finite differences & Y. Gu (UCLA), K.-N. Liou (UCLA) & & Gu and Liou (200I) \\
\hline $\begin{array}{l}\text { Diffusion, finite differences, } \\
\text { multigrid }\end{array}$ & A. Davis (LANL), M. Hall (LANL) & & $N / A$ \\
\hline Diffusion, perturbation & V. Galinsky (Scripps) & & Galinsky and Ramanathan (1998) \\
\hline DA, PDEs, Monte Carlo & A. Davis (LANL) & LANL2 & Davis et al. (1991) \\
\hline DA, discrete space, relaxation & S. Kinne (UMBC) & UMBC4 & $N / A$ \\
\hline DA, discrete space, multigrid & S. Lovejoy (McGill), B. Watson (St. Lawrence) & & N/A \\
\hline $\begin{array}{l}\text { DA, second-order PDEs, } \\
\text { multigrid }\end{array}$ & A. Davis (LANL), M. Hall (LANL) & & $N / A$ \\
\hline \multicolumn{4}{|c|}{ Physics- or statistics-based numerical recipes } \\
\hline Direct-beam IPA & K. F. Evans (UCOL), P. Gabriel (COLS) & & Gabriel and Evans (1996) \\
\hline Tilted IPA & T. Várnai (UMBC), R. Davies (JPL) & & Várnai and Davies (1999) \\
\hline Nonlocal IPA & $\begin{array}{l}\text { A. Marshak (NASA), L. Oreopoulos } \\
(\text { UMBC) }\end{array}$ & UNBP2 & Marshak et al. (1998) \\
\hline Mapping neural networks & F. Szczap (LAMP), C. Cornet (JPL) & UNBPI & Faure et al. (200I) \\
\hline
\end{tabular}

MC OPEN-SOURCE WORKING GROUP. The two most widely used solvers in atmospheric radiation today are the DISORT method Stamnes et al. (1988) for $1 \mathrm{D}$ problems (available via anonymous $\mathrm{ftp}$ at $\mathrm{ftp}: / /$ climatel.gsfc.nasa.gov/wiscombe/Multiple_Scatt/) and SHDOM for 3D problems (publicly available at http://nit.colorado.edu/ evans/shdom.html). Both are algorithms developed thanks to the courageous efforts of only a handful of individuals (Evans in the case of SHDOM, and Laszlo, Stamnes, Tsay, Wiscombe, in the case of DISORT), with little or no help from the RT community.
The Open-Source" Working Group within I3RC takes a different approach by developing the framework of a MC model for solving RT problems in inhomogeneous cloudy atmospheres. I3RC, thus, provides a baseline code that is flexible and robust, and is useful in both teaching and research contexts, but, which, in its initial release, computes only monochromatic domain-averaged reflected and transmitted fluxes and their uncertainty estimates. This code will provide the platform for further developments, and the hope is that the I3RC community will contribute by adding modules for other 
features (radiance and heating rate calculations, spectral integration, etc.)

The I3RC open-source framework is intended to provide pieces of code that can be reused in MC and other RT codes. To that end, following good software engineering practice, a set of modules was defined to represent each portion of the problem. Each module is defined by one or more data structures and a set of procedures (functions and subroutines) that operate on those structures. The modules build on one another, but are structured so that any module can be replaced by another implementation, as long as the new one provides the defined data structures and procedures. These modules are written in standard Fortran 95, to strike a good balance between efficiency and portability.

The nucleus code contains this framework, some associated infrastructure (i.e., translators from other frequently used file formats), and subroutines, integrating monochromatic fluxes with Lambertian surface properties. The code has been tested for all of the I3RC Phase I cases. Implementation of the framework builds on ideas from SHDOM, and from libRadtran (Mayer and Kylling 2005), an open-source library employed by method 11 in Table 1, and methods 2 and 3 in Table 2. We hope that research interests within I3RC will produce communal efforts to develop integrators for computing radiances and for adding thermal sources, so that the model is more helpful to longwave remote sensing and modeling practitioners. Extension to backward MC (as would be used, e.g., to calculate the flux observed by a ground-based pyranometer for different illumination conditions, or as an alternative to the forward model for thermal calculations) is also desirable and is part of our future plans.

Beyond its obvious utility as a classroom/course tool, we anticipate that the I3RC MC open-source model will benefit the atmospheric science community by providing

- a tested, documented benchmark code for 3D RT problems,

- a structure to facilitate development of new RT solvers, and

- a modular "laboratory" to compare and improve MC algorithms.

THE I3RC WEB SITE. A dedicated Web site, (http://i3rc.gsfc.nasa.gov) provides general information on the project's goals and plans, scheduling, documentation and instructions for the experiments, and, most importantly, presents analysis of the results submitted by the participants. A popular feature of the Web site is the interactive tool that displays the results from both phases of I3RC. This tool generates plots of statistics or fields from the data provided. The routines allow the user to have control over the values displayed and the appearance of the plot, which can be printed as a postcript file. Visitors to the Web site who want to view results more quickly also have the option to access static plots, with no user control over default formats.

Figure 8 shows two of the menus of the interactive tool for Phase I results. There is also an interactive tool that can produce plots of the radiation fields themselves. The menu for this tool is shown in Fig. 9. It can be seen that the wealth of I3RC results can be controlled, to a large extent, by the visitors to the I3RC Web site. This is of obvious use to active participants in I3RC, but is also useful to those who are simply users of one of the participating codes, because they can focus on the performance of that particular code.

\section{CONCLUDING REMARKS AND FUTURE} OF I3RC. Under funding from NASA's Radiation Sciences and DOE's ARM programs, the first two phases of I3RC have been largely completed, while the third phase is currently in progress. The close agreement among models after the second round of submissions in Phase I is a testament to the valuable role of I3RC in the detection of coding errors and overall 3D algorithm improvement. Unlike Phase I, Phase II included molecular and aerosol scattering and absorption, along with selected experiments at thermal infrared wavelengths. Both the domain sizes and the design of the experiments themselves raised the degree of complexity, compared to Phase I. As a result, fewer codes participated (SHDOM and $12 \mathrm{MC}$ codes). This fact by itself has underscored a key challenge faced by codes that "dropped out" or other nonparticipating codes-that of becoming able to tackle realistic problems that are most relevant to remote sensing and climate applications, especially those on the leading edge. Agreement between participating codes was, in general, very good. Given the vast number of produced radiation fields, the analysis of the impact of 3D cloud structure under different illumination and viewing geometries remains to be completed, and may be the subject of future publications. Because all results are available to the public, interpretation of the I3RC outputs could potentially become a collective exercise of the entire 3D RT community.

Phase III will employ 3D cloud fields reconstructed from advanced retrieval techniques on common fieldof-view observations of two or more of NASA's Terra 


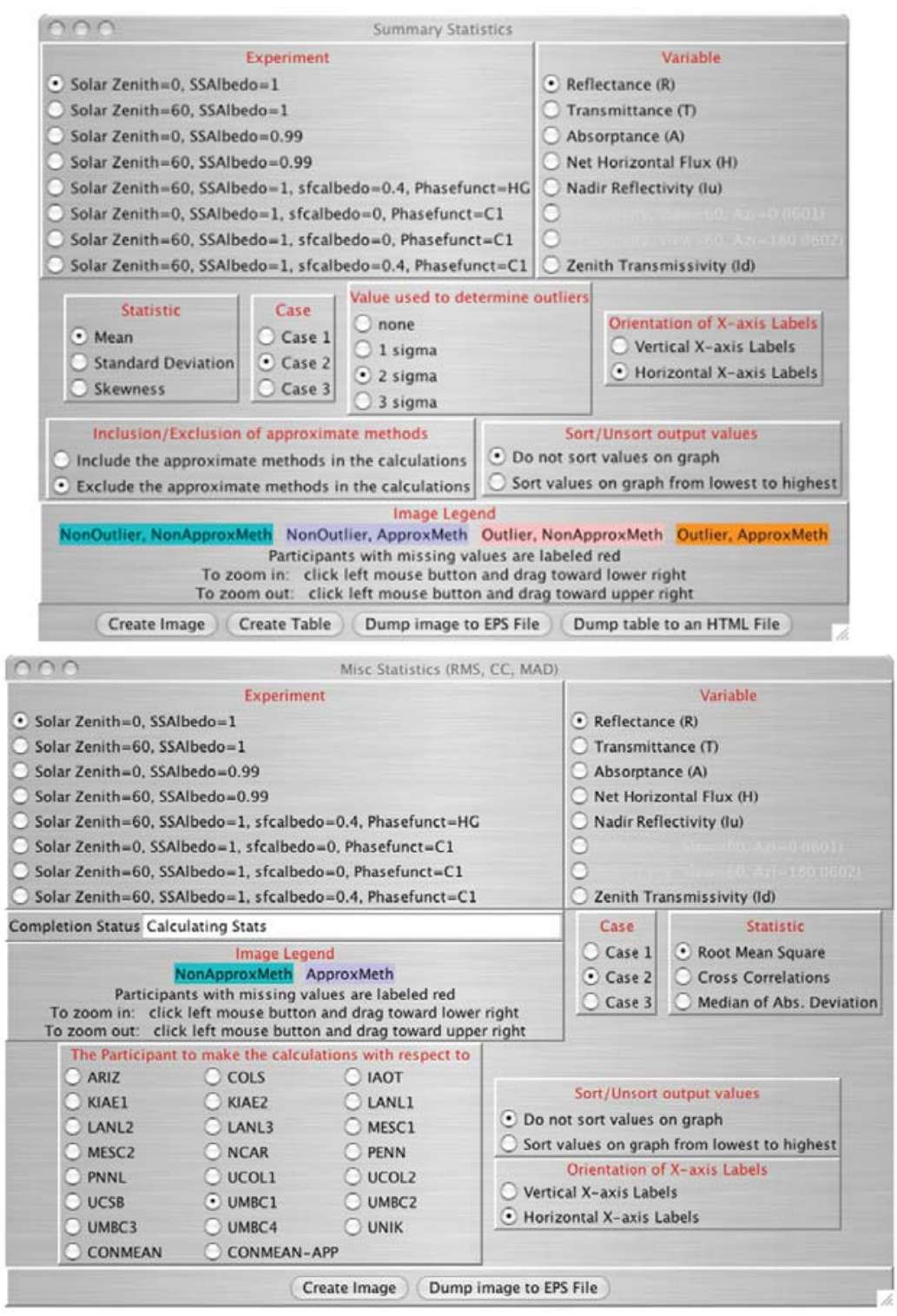

FIG. 8. The interface of the interactive plot tool in the I3RC Web site (http://i3rc.gsfc.nasa.gov) for (top) summary statistics and (bottom) cross-comparison statistics.

spacecraft radiometers, will extend the computations to "searchlight" and lidar-type experiments, and will emphasize improving and sharing radiation codes, aided by working groups on "approximations" and "open source."

Similar to RAMI (Pinty et al. 2001, 2004), its sister $3 \mathrm{D}$ project focusing on vegetated surfaces, I3RC has so far been successful at 1) providing useful benchmarks for code verification and development, 2) helping in identifying weakness, or even bugs, in $3 \mathrm{D}$ algorithms, 3) leading the way in 3D open-source algorithm concepts, and 4) invigorating interest in current 3D RT issues within the atmospheric sciences community. These accomplishments may not cover the full list of initial goals set forth, but are still significant achievements. I3RC is a live project that will carry on in the next few years in order to achieve its remaining goals, as well as to meet challenges such as the following:

1) Diversity of methods. Participating methods that solve the exact 3D RTE on grids include 3D discrete ordinates and SHDOM. All of the other participating methods are based on MC techniques. These include several versions of MC-forward, backward, and conjugated adjoint. Many MC codes share similar techniques, such as a maximum cross section, for speed and variance reduction. The MC approaches solve the exact RTE, and have relatively well-understood errors, so they are useful in evaluating errors of other methods. Three-dimensional methods that begin by approximating the transfer equation, such as diffusion and discrete-angle methods, also participate in I3RC, and can often gain speed advantages over the exact methods, sometimes at the expense of significantly larger errors. Because $3 \mathrm{D}$ approximations were absent in Phase II of I3RC, more efforts shall be made to meet the challenge of diversity.

2) Applicability. For I3RC to benefit both remote sensing and climate modeling, it is necessary for I3RC computations to include a wide variety of radiances, fluxes, and heating rates. Outputs quickly multiply. Even the restricted set of fields and outputs of Phase I led to 1000 comparison plots. For these to be useful and accessible requires a simple and flexible Web interface, which has been provided in the form of interactive analysis and plotting tools. These will continue to be improved in order to fulfill I3RC's educational objective.

3) Scalability. Input cloud fields for I3RC must have a spatial resolution that is capable of resolving 
the typical photon mean free path on the order of $100 \mathrm{~m}$, in order to represent 3D radiation effects, yet cover a sufficiently large domain to fairly represent cloud variability unresolved by GCMs, with grid boxes typically exceeding $\sim 50 \mathrm{~km}$ horizontally. These two goals are not simultaneously achievable at present with commonly available computing resources. The I3RC baseline cases handle this problem by choosing relatively small domains within which $3 \mathrm{D}$ effects are well resolved, and assuming that plane-parallel biases in domain-averaged quantities can be scaled up to the larger scales needed by models. This relies on empirical and cloud-resolving modeling studies of the scaling properties of clouds, which are still ongoing.

I3RC and RAMI, along with parallel efforts relating to 3D RT in sea ice, snow, and other components of the climate system, continue to benefit from overlapping issues and solutions. Given these interactions, a new 3D RT working group has been organized, chaired by one of the authors (Cahalan) and sponsored by the IRC. The 3D RT group is coordinated by an executive committee that comes from a cross section of the 3D RT community. The group hopes to share tools and insights gleaned from the variety of applications in which they are engaged, and to encourage and enable the extension of 3D RT to new applications in earth science.

We are looking forward to a greater exposure of graduate students to the world of $3 \mathrm{D}$ atmospheric radiation in academic curricula, and hope the imminent publication of the first monograph exclusively dedicated to the subject (Marshak and Davis 2005) will help in that regard. With a larger audience, there is reason to be optimistic for a bright 3D RT future in climate research and remote sensing alike. While 3D RT models are by no means perfect, or in perfect agreement, they have been steadily converging toward common answers, so investigation of approaches that would make them suitable for routine meteorological and climatic applications should intensify. We expect the I3RC project to be one day viewed as a main contributor to this effort and to the advancement of the field of atmospheric radiation in general.

ACKNOWLEDGEMENTS. I3RC is jointly funded by the US Department of Energy (DOE) Atmospheric Radiation Measurement Program (ARM) and by the NASA Radiation Sciences Program (RSP), and is also sponsored by the GEWEX Radiation Panel (GRP) and the International Radiation Commission (IRC). We would like to specifically acknowledge the financial support by DOE via interagency agreement DE-AI02-00ER62939 and NASA Grant 621-30-86, 622-42-57; and the moral support and encouragement of Wanda Ferrell of the DOE ARM Program, Don Anderson and Hal Maring of the NASA RSP, and William Rossow of the GRP and Herbert Fisher of the IRC. We would also like to thank the 3D RT community at large for its remarkable efforts to advance the field in the last three decades. The research described in this paper by Roger Davies was carried out initially at the University of Arizona and then at the Jet Propulsion Laboratory, California Institute of Technology, under a contract with the National Aeronautics and Space Administration. 
APPENDIX: LIST OF ACRONYMS

1D

3D

ARIZ

ARM

ASTER

CIRES

COLS

CPU

CSRM

$\mathrm{Cu}$

DA

DOE

DISORT

DZLR

ED3D

EOS

EVENT

FIRE

GCM

GCSS

GEWEX

GISS

GRP

GSFC

IAOT

ICA

ICOM

ICRCCM

IMCL

IR

IRC

I3RC

IPA

ISCCP

JPL

KIAE

LAMP

LANL

LARC

LES

libRadtran

LOA

MC

MESC

MISR

MMCR

MODIS

MMF

MWR

NASA

NCAR

NIPA
One-dimensional

Three-dimentional

University of Arizona

Atmospheric Radiation Measurement Program

Advanced Spaceborne Thermal Emission and Reflection Radiometer

Cooperative Institute for Research in Environmental Sciences

Colorado State University

Central processing unit

Cloud system resolving model

Cumulus (cloud field)

Discrete angle

Department of Energy

Discrete ordinates radiative transfer (code)

Deutsches Zentrum für Luft und Raumfahrt

Delta-Eddington in 3D

Earth Observing System

Even-parity neutron transport

First ISCCP Regional Experiment

General circulation model

GEWEX Cloud System Study

Global Energy and Water Cycle Experiment

Goddard Institute for Space Studies

GEWEX Radiation Panel

NASA Goddard Space Flight Center

Institute of Atmospheric Optics at Tomsk

Independent column approximation [aka independent pixel approximation (IPA)]

Institute of Computational Mathematics

Intercomparison of Radiation Codes in Climate Models

Imperial College of London

Infrared

International Radiation Commission

Intercomparison of 3D Radiation Codes (available online at http://i3rc.gsfc.nasa.gov)

Independent pixel approximation [aka independent column approximation (ICA)]

International Satellite Cloud Climatology Project

Jet Propulsion Laboratory

Kurchatov Institute

Laboratoire de Météorologie Physique

Los Alamos National Laboratory

NASA Langley Research Center

Large eddy simulation (model)

$\mathrm{C}$ and Fortran library of radiative transfer routines

Laboratoire d'Optique Atmosphérique

Monte Carlo

Meteorological Service of Canada

Multi-Angle Imaging Spectrometer

Millimeter cloud radar

Moderate Resolution Imaging Spectroradiometer

Multiscale modeling framework

Microwave radiometer

National Aeronautics and Space Administration

National Center for Atmospheric Research

Nonlocal independent pixel approximation 


$\begin{array}{ll}\text { NOAA } & \text { National Oceanic and Atmospheric Administration } \\ \text { PDE } & \text { Partial differential equation } \\ \text { PENN } & \text { The Pennsylvania State University } \\ \text { PNNL } & \text { Pacific Northwest National Laboratory } \\ \text { RAMI } & \text { Radiation Transfer Model Intercomparison } \\ \text { RT } & \text { Radiative transfer } \\ \text { RSP } & \text { Radiation Sciences Program (NASA) } \\ \text { RTE } & \text { Radiative transfer equation } \\ \text { Sc } & \text { Stratocumulus (cloud field) } \\ \text { SHDOM } & \text { Spherical Harmonic Discrete Ordinate Method (code) } \\ \text { TWODANT } & \text { Two-dimensional diffusion-accelerated neutral-particle transport } \\ \text { UCLA } & \text { University of California, Los Angeles } \\ \text { UCOL } & \text { University of Colorado } \\ \text { UCSB } & \text { University of California, Santa Barbara } \\ \text { UMBC } & \text { University of Maryland, Baltimore County } \\ \text { UMCP } & \text { University of Maryland, College Park } \\ \text { UNBP } & \text { Université Blaise Pascal } \\ \text { UNIK } & \text { University of Kiel } \\ \text { UNSW } & \text { University of New South Wales }\end{array}$

\section{REFERENCES}

Alcouffe, R. E., R. S. Baker, F. W. Brinkley, D. R. Marr, R. D. O'Dell, and W. F. Walters, 1997: DANTSYS: A Diffusion Accelerated Neutral Particle Transport (UC-705), issued 06/95, revised 03/97. Los Alamos National Laboratory.

Avaste, O. A., and G. M. Vainikko, 1974: Solar radiation transfer in broken clouds. Izv. Acad. Sci. USSR Atmos. Oceanic Phys., 10, 1054-1061.

Barker, H. W., J.-J. Morcrette, and G. D. Alexander, 1998: Broadband solar fluxes and heating for atmospheres with 3D broken clouds. Quart. J. Roy. Meteor. Soc., 124, 1245-1271.

_ , G. L. Stephens, and Q. Fu, 1999: The sensitivity of domain averaged solar fluxes to assumptions about cloud geometry. Quart. J. Roy. Meteor. Soc., 125, 2127-2152.

— , R. K. Goldstein, and D. E. Stevens, 2003a: Monte Carlo simulation of solar reflectances for cloudy atmospheres. J. Atmos. Sci., 60, 1881-1894.

— solar radiative transfer models: Interpretation and handling of unresolved clouds. J. Climate, 16, 2676-2699.

Cahalan, R. F., 1989: Overview of fractal clouds. Advances in Remote Sensing. A. Deepak Publishing, 371-388.

—_, and R. Davies, Eds., 2000: Intercomparison of Three-Dimensional Radiation Codes: Abstracts of the First and Second International Workshops. University of Arizona Press, 122 pp.

—, W. Ridgway, W. J. Wiscombe, S. Gollmer, and Harshvardhan, 1994: Independent pixel and Monte Carlo estimates of stratocumulus albedo. J. Atmos. Sci., 51, 3776-3790.

Cess, R. D., and Coauthors 1989: Interpretation of cloud-climate feedback as produced by 14 atmospheric general circulation models. Science, 245, 513-515.

-_, and Coauthors, 1990: Intercomparison and interpretation of climate feedback processes in 19 atmospheric general circulation models. J. Geophys. Res., 95, 16 601-16 615.

— spheric general circulation models: An update. J. Geophys. Res., 101, 12 791-12 794.

Chambers, L., B. Wielicki, and K. F. Evans, 1997: On the accuracy of the independent pixel approximation for satellite estimates of oceanic boundary layer cloud optical depth. J. Geophys. Res., 102, 1779-1794.

Cole, J., 2005: Assessing the importance of unresolved cloud-radiation interactions in atmospheric global climate models using the multiscale modeling framework. Ph.D. thesis, The Pennsylvania State University, $157 \mathrm{pp}$.

Davies, R., 1978: The effect of finite cloud geometry on the 3D transfer of solar irradiance in clouds. J. Atmos. Sci., 35, 1712-1725.

Davis, A. B., and A. Marshak, 2001: Multiple scattering in clouds: Insights from three-dimensional diffusion/P1 theory. Nuclear Sci. Eng., 137, 251-280.

—, S. M. Lovejoy, and D. Schertzer, 1991: Discrete angle radiative transfer in a multifractal medium. 
Wave Propagation and Scattering in Varied Media II, SPIE, 37-59.

Ellingson, R. G., and Y. Fouquart, 1991: The intercomparison of radiation codes in climate models: An overview. J. Geophys. Res., 96, 8925-8927.

Evans, K. F., 1998: The spherical harmonics discrete ordinate method for three-dimensional atmospheric radiative transfer. J. Atmos. Sci., 55, 429-446.

Faure, T., H. Isaka, and B. Guillemet, 2001: Neural network analysis of the radiative interaction between neighboring pixels in inhomogeneous clouds. $J$. Geophys. Res., 106, 14 465-14 484.

Fu, Q., S. K. Krueger, and K.-N. Liou, 1995: Interactions of radiation and convection in simulated tropical cloud clusters. J. Atmos. Sci., 52, 1310-1328.

Gabriel, P. M., and K. F. Evans, 1996: Radiative transfer methods for calculating domain-averaged solar fluxes in inhomogeneous clouds. J. Atmos. Sci., 53, 858-877.

Galinsky, V. L., and V. Ramanathan, 1998: 3D radiative-transfer in weakly inhomogeneous media. Part I: Diffusive approximation. J. Atmos. Sci., 55, 2946-2959.

Geogdzhaev, I. V., T. V. Kondranin, A. N. Rublev, and N. E. Chubarova, 1997: UV radiation transfer through broken cloud fields: Modeling and comparison with measurements. Izv. Atmos. Oceanic Phys. 33, 630-635.

Glasov, G. N., and G. A. Titov, 1975: Stochastic characteristics of the extinction coefficient in broken clouds. Izv. Vuzov. Physics, 9, 151-154.

Gu, Y., and K.-N. Liou, 2001: Radiation parameterization for three-dimensional inhomogeneous cirrus clouds: Application to climate models. J. Climate, 14, 2443-2457.

Kassianov, E. I., and Y. L. Kogan, 2002: Spectral dependence of radiative horizontal transport in stratocumulus clouds and its effect on near-IR absorption. J. Geophys. Res., 107 (D23), 4712, doi:10.1029/2002JD002103.

Kiehl, J. T., and K. E. Trenberth, 1997: Earth's annual global mean energy budget. Bull. Amer. Meteor. Soc., 78, 197-208.

Lenoble, J., Ed., 1985: Radiative Transfer in Scattering and Absorbing Atmospheres: Standard Computational Procedures, Deepak, 300pp.

Macke, A., D. Mitchell, and L. von Bremen, 1999: Monte Carlo radiative transfer calculations for inhomogeneous mixed phase clouds. Phys. Chem. Earth B, 24, 237-241.

Marchuk, G., G. Mikhailov, M. Nazaraliev, R. Darbinjan, B. Kargin, and B. Elepov, 1980: The Monte Carlo Methods in Atmospheric Optics. Springer-Verlag, 208 pp.
Marshak, A., and A. B. Davis, Eds., 2005: Radiative Transfer in Cloudy Atmospheres. Springer Verlag, 701 pp.

- - — W. J. Wiscombe, and R. F. Cahalan, 1995: Radiative smoothing in fractal clouds. J. Geophys. Res., 100, 26 427-26 261.

- - — R. F. Cahalan, and W. J. Wiscombe, 1998: Nonlocal independent pixel approximation: Direct and inverse problems. IEEE Trans. Geosci. Remote Sens., 36, 192-205.

—, L. Oreopoulos, A. Davis, W. J. Wiscombe, and R. F. Cahalan, 1999: Horizontal radiative fluxes in clouds and accuracy of the Independent Pixel Approximation at absorbing wavelengths. Geophys. Res. Lett., 26, 1585-1588.

Mayer, B., and A. Kylling, 2005: The libRadtran software package for radiative transfer calculationsdescription and examples of use. Atmos. Chem. Phys., 5, 1855-1877.

McKee, T. B., and S. K. Cox, 1974: Scattering of visible radiation by finite clouds. J. Atmos. Sci., 31, 1885-1892.

Moeng, C.-H., and Coauthors, 1996: Simulation of a stratocumulus-topped planetary boundary layer: Intercomparison among different numerical codes. Bull. Amer. Meteor. Soc., 77, 261-278.

Mullamaa, Y. R., M. A. Sulev, V. K. Poldmaa, H. A. Ohvril, H. J. Nrylisk, M. I. Allenov, L. G. Tchuhakov, and A. F. Kuusk, 1972: Stochastic structure of cloud and radiation fields. Academy of Sciences of Estonian SSR. (1975; NASA Technical Translation TT F-822), 192.

O'Hirok, W., and C. Gautier, 1998: A three-dimensional radiative transfer model to investigate the solar radaition within a cloudy atmosphere. Part I: Spatial effects. J. Atmos. Sci., 55, 2162-2179, 1998.

Oreopoulos, L., and R. Davies, 1998: Plane parallel albedo biases from satellite observations. Part I: Dependence on resolution and other factors. J. Climate, 11 , 919-932.

_-, R. Cahalan, A. Marshak, and G. Wen, 2000: A new normalized difference cloud retrieval technique applied to Landsat radiances over the Oklahoma ARM Site. J. Appl. Meteor., 39, 2305-2320.

Partain, P. T., A. K. Heidinger, and G. L. Stephens, 2000: High spectral resolution atmospheric radiative transfer: Application of the equivalence theorem. $J$. Geophys. Res., 105, 2163-2177.

Pinty, B., and Coauthors, 2001: The radiation transfer model intercomparison (RAMI) exercise. J. Geophys. Res., 106, 11 937-11956.

—_, and Coauthors, 2004: The radiation transfer model intercomparison (RAMI) exercise: Results from the second phase. J. Geophys. Res., 109, D06210, doi: 10.1029/2003JD004252. 
Polonsky, I. N., M. A. Box, and A. B. Davis, 2003: Radiative transfer through inhomogeneous turbid media: Implementation of the adjoint perturbation approach at the first-order. J. Quant. Spectrosc. Radiat. Transfer, 78, 85-98.

$\mathrm{Qu}, \mathrm{Z} ., 1999$ : On the transmission of ultraviolet radiation in horizontally inhomogeneous atmospheres: A threedimensional approach based on the delta-Eddington Approximation. Ph.D. thesis, University of Chicago, $161 \mathrm{pp}$.

Ramanathan, V., R. D. Cess, E. F. Harrison, P. Minnis, B. R. Barkstrom, E. Ahmad, and D. Hartmann, 1989: Cloud-radiative forcing and climate: Results from the Earth-radiation Budget Experiment. Science, 243, 57-63.

Randall, D., M. Khairoutdinov, A. Arakawa, and W. Grabowski, 2003: Breaking the cloud parameterization deadlock. Bull. Amer. Meteor. Soc., 84, 1547-1564.

Rublev, A. N., A. B. Uspensky, A. N. Trotsenko, T. A. Udalova, and E. V. Volkova, 2004: Detection and assessment of a cloud using data from atmospheric IR sensors with high spectral resolution (in Russian). Earth Res. Space, 2, 1-9.

Stamnes, K., S.-C. Tsay, W. J. Wiscombe, and K. Jayaweera, 1988: Numerically stable algorithm for discrete-ordinate-method radiative transfer in multiple scattering and emitting layered media. Appl. Opt., 27, 2502-2509.
Stevens, B., C.-H. Moeng, and P. P. Sullivan, 1999: Largeeddy simulations of radiatively driven convection: Sensitivities to the representation of small scales. J. Atmos. Sci., 56, 3963-3984.

Takara, E. E., and R. G. Ellingson, 1996: Scattering effects on longwave fluxes in broken cloud fields. J. Atmos. Sci., 53, 1464-1476.

Thomas, G. E., and K. Stamnes, 1999: Radiative Transfer in the Atmosphere and Ocean. Cambridge University Press, 517 pp.

Trasi, N. S., C. R. E. de Oliveira, and J. D. Haigh, 2004: A finite element-spherical harmonics model for radiative transfer in inhomogeneous clouds: Part I: The EVENT model. Atmos. Res., 72, 197-221.

Várnai, T., and R. Davies, 1999: Effects of cloud heterogeneities on shortwave radiation: Comparison of cloud-top variability and internal heterogeneity. J. Atmos. Sci., 56, 4206-4224.

—-, and A. Marshak, 2002: Observations and analysis of 3-dimensional radiative effects that influence MODIS cloud optical thickness retrievals. J. Atmos. Sci., 59, 1607-1618.

—, and —, 2003: A method for analyzing how various parts of clouds influence each other's brightness. J. Geophys. Res. 108, 4706, doi: 10.1029/2003JD003651.

Wielicki, B. A., and R. M. Welch, 1986: Cumulus cloud properties derived using Landsat satellite data. $J$. Climate Appl. Meteor., 25, 261-276. 